\title{
Fatal methane and cyanide poisoning as a result of handling industrial fish: a case report and review of the literature
}

\author{
M A Cherian, I Richmond
}

\begin{abstract}
The potential health hazards of handling industrial fish are well documented. Wet fish in storage consume oxygen and produce poisonous gases as they spoil. In addition to oxygen depletion, various noxious agents have been demonstrated in association with spoilage including carbon dioxide, sulphur dioxide, and ammonia. A fatal case of methane and cyanide poisoning among a group of deep sea trawler men is described. Subsequent independent investigation as a result of this case led to the discovery of cyanides as a further potential noxious agent. This is thus the first case in which cyanide poisoning has been recognised as a potentially fatal complication of handling spoiled fish. The previous literature is reviewed and the implications of the current case are discussed.

(F Clin Pathol 2000;53:794-795)
\end{abstract}

Keywords: industrial fish; methane; cyanide

Case report

A fatal accident occurred aboard a stern freezing trawler 40 miles off the coast of Mauritania in West Africa while engaged in pelagic trawling for fish. The vessel was close to the end of a 30 day spell of fishing and was sorting one of her last hauls before proceeding to land the catch. The warm temperature and failure to clean the storage tank immediately after its previous use, leaving a mixture of sea water and fish to spoil, contributed to the unfortunate events that followed.

One of the crew opened the side door of a refrigerated salt water tank to flush it out before loading it with freshly caught fish. The crewman collapsed immediately after opening the door, apparently having been overcome by toxic fumes. Unaware of the dangers several crewmen went to his aid and were also overcome. By the time the situation was rectified three crewmen had died and six suffered other injuries.

All three of those who died collapsed within

Department of Pathology, Castle Hill Hospital, Castle Road, Cottingham, North Humberside, HU16 5JQ, UK

M A Cherian

I Richmond

Correspondence to: Dr Cherian

Accepted for publication 10 April 2000

men suffered a variety of a symptoms inclu blackouts, seizures, chest pain, vomiting, and difficulty in breathing.

One of the dead crew members underwent a postmortem examination after repatriation of the body a few days after the incident. At necropsy, the body was that of a moderately built 30 year old white man. Apart from early postmortem decomposition the body was partially covered in fish scales. No gross abnormal- ity was noted on external and internal examination. The salient findings were limited to toxicological analysis of samples obtained at the time of necropsy. Several volatile agents were detected in the blood and whole lungs. One of these was shown to be methane by gas chromatography and mass spectrometry. A blood cyanide concentration of $<50 \mu \mathrm{g} /$ litre was also demonstrated, as was a carboxyhaemoglobin concentration of $14 \%$ of total haemoglobin. The demonstration of methane and cyanide in both blood and whole lung samples a few days after death was considered very important. No other drugs or toxins were found and in particular no refrigerants or dichloromethane based chemicals (such as paint strippers) were identified. Histological analysis of various tissues at necropsy failed to reveal any abnormality and the cause of death was given as inhalation of toxic fumes.

As part of the investigation conducted by the Department of Transport into this case, and as a direct result of the necropsy findings, a report was commissioned by the food refrigeration and process engineering research centre (FRPERC) of the University of Bristol into the noxious agents produced by rotten fish. ${ }^{1}$

In the main experiment, six replicate samples of a $50 \%$ sardenella/sea water mixture were sealed and placed in four different containers at $5^{\circ} \mathrm{C}, 20^{\circ} \mathrm{C}, 35^{\circ} \mathrm{C}$, and $45^{\circ} \mathrm{C}$. Dangerous concentrations of hydrogen cyanide, hydrogen sulphide, and carbon dioxide were measured in the containers held at $20^{\circ} \mathrm{C}, 35^{\circ} \mathrm{C}$, and $45^{\circ} \mathrm{C}$. The rate of formation of all these gases increased with increasing temperature.

In the container held at $35^{\circ} \mathrm{C}$ (the temperature most likely to simulate events on board the vessel) concentrations thought to be immediately damaging to life and health (IDLH concentrations $>50 \mathrm{ppm}$ (parts per million) for hydrogen cyanide, $>100$ ppm for hydrogen sulphide, and $>4 \%$ for carbon dioxide) were reached within 28 hours. The IDLH (immediately damaging to life and health) concentration is that from which escape is deemed possible if all respiratory protection fails. Extrapolation of the results suggested that concentrations likely to cause death within minutes would be attained in 36 hours. ${ }^{1}$

\section{Discussion}

Stored wet fish spoil and produce toxic gases. ${ }^{2}$ The risk is especially high in industrial fishing because fish are stored in bulk without ice in closed spaces. Factors that aggravate fish spoilage are a relatively high temperature and lack of ventilation, and under these conditions a 
dangerous atmosphere can be produced within hours. The initial flora of North Sea fish consisted mostly of moraxella, arthrobacter, pseudomonas, flavobacterium, cytophage, and micrococcus but pseudomonas became more dominant on prolonged storage. ${ }^{3}$ Pseudomonas and hydrogen sulphide producing Altermonas putrefaciens are responsible for spoilage even though moraxella, acinetobacter, and coryneforms are present in large numbers. ${ }^{3}$ Previous reference has been made to the production of carbon dioxide, sulphur dioxide, and ammonia from rotten fish. In the present case the noxious agents appear to have been methane and cyanide. Methane is a well known product of putrefaction, but it is interesting to speculate how a potentially fatal load of cyanide can build up in a catch of fish, particularly because this is the first recognised case.

Cyanide is a secondary metabolite formed by the oxidation of glycine to hydrogen cyanide and carbon dioxide by bacteriaChromobacterium violaceum and pseudomonas. ${ }^{4}$ Cyanide binds irreversibly with cytochrome c oxidase in both transient turnover and stable states, and as such acts as a metabolic poison. ${ }^{5}$ The rate of cyanide production increases at higher temperatures, with maximum cyanogenesis occurring at $25-30^{\circ} \mathrm{C} .{ }^{6} \mathrm{Hydrogen}$ cyanide produced by Pseudomonas aeruginosa in a synthetic medium required aerobiosis. ${ }^{6}$

The simulated conditions generated by the team from the University of Bristol were likely to have closely mirrored those present in the refrigerated salt water tank on board the trawler at the time. Certainly, the speed with which the fatally injured crewmen were seen to collapse and the range of symptoms demonstrated by the survivors are in keeping with the effects of a metabolic poison such as cyanide. Previous reports of industrial incidents related to decaying fish have failed to mention cyanide as a potential toxic agent.

Pseydomonas putrefaciens is an organism found on fish producing hydrogen sulphide. ${ }^{7}$ We are aware of two other cases of caused by the inhalation of toxic fumes from decaying fish ${ }^{8}$; hydrogen sulphide was presumed to be the main cause and cyanides were not found. Proteus, a much less common organism on fish, produces hydrogen sulphide ${ }^{8}$ and Pseudomonas putrefaciens is another organism found on fish that produce hydrogen sulphide. ${ }^{8}$ Hydrogen sulphide is associated with the risk of hypoxic brain damage. In both these cases of death caused by the inhalation of toxic fumes, consciousness was lost immediately. Follow up of these patients revealed various neurological abnormalities such as reduced memory, irritability, reduced motor function, reduced vibra- tion and temperature sense, ataxia, positive rhombergs sign, considerably reduced learning and retention, and dementia. The computed tomography scan showed widened ventricles and cortical atrophy in one of the cases. Interestingly, both men were awarded a disability pension within a year of the accident. Blood sulphide may be used as an indicator of excessive hydrogen sulphide exposure but the sample has to be taken as soon as possible (not later than two hours) and analysed without delay. ${ }^{7}$ Clearly, this was not possible in this case. Hydrogen sulphide is associated with decreased activity of haem synthesising enzymes especially amino leuvalinic acid synthase and haem synthase. ${ }^{9}$

The spoiled fish in our case were oily fish and it is interesting to speculate whether white fish would spoil in a similar manner. The organisms associated with North Sea fish have previously been listed. In warmer climates, different flora predominate such as bacillus species, microccocus, and coryneforms. ${ }^{10}$ Would the products of spoilage be different? This might be an avenue for further research.

In conclusion, a fatal case of inhalation of toxic fumes related to decaying fish is reported. The putative agents involved in this case appear to be methane and/or cyanide. Awareness of the health hazards involved in the handling of industrial fish is important, particularly for those working in the vicinity of fishing communities.

We thank the marine accident investigation branch of the Department of Transport for allowing us to publish the case and for allowing the study undertaken by the food refrigeration and process engineering research centre (FRPERC), University of Bristol as a result of this case.

1 Lang JS. Analysis. Report of marine accident investigation branch of the DETR into fo Atlantic Princess. London: Her Majesty's Stationary Office, 1997;2:17-19.

2 Ward A. Health hazards of handling industrial fish. Ministry of Agriculture, Fisheries and Food. Torry Research Station. Torry advisory note No. 78. Edinburgh: Her Majesty's Stationary Office, 1978:1-3.

3 Stenstrom M, Molin G. Classification of the spoilage flora of fish with special reference to Shewanella putrefaciens. $\mathcal{f}$ Appl Bacteriol 1990;68:601-18.

4 Jones MG, Bickar D, Wilson MT, et al. A reexamination of Jones MG, Bickar D, Wilson MT, et al. A reexamination of
the reaction of cyanide with cytochrome c oxidase. Biochem the reaction of cyanid

5 Castric PA. Hydrogen cyanide, a secondary metabolite of Pseudomonas aeruginosa. Can f Microbiol 1975;21:61318

6 Castric PA. Hydrogen cyanide production by Pseudomonas aeruginosa at reduced oxygen levels. Can F Microbiol 1983; 29:1344-9.

7 Levin RE. Detection and incidence of specific species of spoilage bacteria on fish. Appl Microbiol 1968;16:1734-7.

8 Tvedt B, Skyberg K, Aaserud O, et al. Brain damage caused by hydrogen sulphide - a follow up study of six patients. Am $\mathscr{f}$ Ind Med 1991;20:91-101.

9 Jappinen P, Tenhunen R. Hydrogen sulphide poisoning: Jappinen P, Tenhunen R. Hydrogen sulphide poisoning:
blood sulphide concentration and changes in haem blood sulphide concentration and chang
metabolism. Brf Ind Med 1990;47:283-5.

10 Gillespie NC, Macrae IC. The bacterial flora of some Queensland fish and its ability to cause spoilage. $\mathcal{F} A p p l$ Bacteriol 1975;39:91-100. 